\title{
Comparison and Analysis of Calculation Models of Solar Irradiance on Inclined Surface Based on Numerical Simulation Method
}

\author{
Chenglong Luo ${ }^{1, *}$, Dan $\mathrm{Sun}^{1}$, Lijie Xu ${ }^{2}$, Jihai Xiong ${ }^{1}$ and Mengyin Liao ${ }^{1}$ \\ ${ }^{1}$ Institute of Energy Research, Jiangxi Academy of Sciences, Nanchang 330096, China \\ ${ }^{2}$ Department of Thermal Science and Energy Engineering, University of Science and Technology of China, Hefei 230027, China \\ *Corresponding author
}

\begin{abstract}
The present paper summarized the results of the most commonly adopted calculation models for total solar irradiance on inclined surface. The solar irradiance on inclined surface in Beijing was taken as an example and was simulated using Liu and Jordan, Klucher, Hay, and Perez sky models and the results were analyzed in a variety of circumstances. The modified Klucher model was improved with the introduction of the correction for tilt angle $\beta=0^{\circ}$ and the suitability of all the five calculation models was analyzed.
\end{abstract}

Keywords-solar radiation; inclined surface; diffuse irradiance; direct irradiance; reflect irradiance

\section{INTRODUCTION}

Solar energy is an important alternative for fossil fuel as it is a clean and renewable energy. Regarding the application of solar energy in buildings, tilt angle usually exists between the receiving surface of solar energy and the horizontal plane. Thereby, the calculation of solar irradiance on the inclined surface is very important to the investigation on the use of solar energy, and many studies have been done on this topic. ElSebaii et al. ${ }^{[1]}$ calculated direct solar irradiance and diffuse irradiance for horizontal plane and inclined surface in Jidda city, Saudi Arabia. Karakoti et al. ${ }^{[2]}$ studied the empirical calculation formula of diffuse irradiance by including the effects of solar radiance duration, temperature and relative humidity on diffuse irradiance. Based on measured values of solar irradiance on a horizontal plane, Notton et al. ${ }^{[3]}$ studied and calculated the solar radiance on inclined surface by multiple calculation models and their combinations, and carried out the error analysis on the results. Pandey et al. ${ }^{[4]}$ studied the solar irradiance calculation for inclined surface in India and analyzed and compared various calculation models concluding that Klucher model gives the best calculation result. Amrouche et al. ${ }^{[5]}$ proposed to establish a neural network model for predicting total solar irradiance on horizontal plane.

The calculation of solar irradiance on inclined surface is crucial to performance evaluation and optimization of solar energy technologies that are applied in buildings. The solar irradiance received by an inclined surface does not only relate to the factors such as local latitude, date, time, and weather, but also to the tilt angle and the azimuth angle of the surface. Tilt angle and azimuth angle of the inclined surface are controllable factors that can affect the solar irradiance on an inclined surface. At present, for various regions and time periods, many studies have been carried out on the best tilt angle of inclined surface ${ }^{[6-9]}$ to achieve the greatest solar irradiance.

The total solar irradiance (TSI) on an inclined surface is the sum of direct beam irradiance, sky diffuse irradiance and ground reflected irradiance ${ }^{[10]}$. Currently, relatively unified calculation formulas are available for direct beam and groundreflected irradiances while different calculation models are proposed for diffuse sky irradiance. To further understand and master the features of calculation models for solar irradiance on an inclined surface, the present work compares and analyzes the calculated values for various tilt angles and in different weather conditions for Beijing city using four irradiance calculation models, including Liu and Jordan, Klucher, Hay, and Perez model. Furthermore, Klucher model is corrected with the introduction of tilt angle $\beta=0^{\circ}$ to implement better numerical calculation and analysis on photovoltaic and thermal technologies of solar energy.

\section{CALCULATION OF SOLAR IRRADIANCE ON INCLINED SURFACE}

The installation of solar energy utilization equipment such as solar photovoltaic array and solar thermal collector, as well as the solar facilities installed on the wall or envelope of buildings, usually requires a certain tilt angle against horizontal plane to receive high solar irradiation. Solar irradiance calculation on inclined surface is very important to the development and evaluation of utilization technologies for solar energy. The total solar irradiance received by a surface tilted with an angle $\beta$ in respect to the horizontal plane, $\mathrm{I}_{\beta}$, is the sum of direct solar irradiance $\left(\mathrm{I}_{\mathrm{b} \beta}\right)$, sky diffuse irradiance $\left(\mathrm{I}_{\mathrm{d} \beta}\right)$ and solar radiation reflected from the ground $\left(\mathrm{I}_{\mathrm{r} \beta}\right)$ :

$$
I_{\beta}=I_{\mathrm{b} \beta}+I_{\mathrm{r} \beta}+I_{\mathrm{d} \beta}
$$

\section{A. $\quad$ Direct Beam Irradiance $I_{\mathrm{b} \beta}$}

$$
I_{\mathrm{b} \beta}=I_{\mathrm{bh}} \cdot \frac{\cos \theta}{\cos \theta_{\mathrm{z}}}
$$


where $I_{\mathrm{bh}}$ is direct irradiance on horizontal plane obtained by solar radiometer or calculation model (e.g. Hottel model); $\theta$ is incidence angle of sunlight on inclined surface, $\theta_{z}$ is solar zenith angle. [11].

Incidence angle of sunlight on inclined surface $\theta$ is given by

$$
\begin{aligned}
\cos \theta= & \cos \delta \cos \beta \cos \Phi \cos \omega+\sin \delta \sin \Phi \cos \beta \\
& +\cos \delta \sin \varphi \sin \beta \sin \omega+\cos \delta \cos \omega \sin \Phi \sin \beta \cos \varphi \\
& -\sin \delta \cos \Phi \sin \beta \cos \varphi
\end{aligned}
$$

Solar zenith angle is determined by local latitude angle $\Phi$, hour angle $\omega$ and declination angle $\delta$, i.e. ${ }^{[12]}$

$$
\cos \theta_{\mathrm{z}}=\cos \omega \cos \delta \cos \Phi+\sin \delta \sin \Phi
$$

\section{B. Ground-Reflected Irradiance $I_{\mathrm{r} \beta}$}

$$
I_{\mathrm{r} \beta}=\frac{1}{2} \rho(1-\cos \beta)\left(I_{\mathrm{bh}}+I_{\mathrm{dh}}\right)
$$

where $I_{\mathrm{dh}}$ is diffuse irradiance on horizontal plane obtained by solar radiometer or calculation model (e.g. Hottel model); $\rho$ is surface albedo.

\section{Sky Diffuse Irradiance $I_{\mathrm{d} \beta}$}

Nowadays many calculation models for inclined surface solar irradiance have been proposed. Furthermore, focusing on some regions, researchers compared the calculation results with measured ones to verify the accuracy of the models.

In 1962, Liu and Jordan proposed an isotropic model whose expression is relatively simple, given by ${ }^{[13]}$

$$
I_{\mathrm{d} \beta}=I_{\mathrm{dh}} \cdot \frac{1+\cos \beta}{2}
$$

Klucher considered the effect of clouds in the sky and proposed a diffuse irradiance model as ${ }^{[14]}$

$$
\begin{aligned}
& I_{\mathrm{d} \beta}=I_{\mathrm{dh}} \cdot \frac{1+\cos \beta}{2} \cdot\left[1+\left(1-\frac{I_{\mathrm{dh}}^{2}}{I_{\mathrm{Th}}^{2}}\right)\left(\sin \frac{\beta}{2}\right)^{3}\right] . \\
& {\left[1+\left(1-\frac{I_{\mathrm{dh}}^{2}}{I_{\mathrm{Th}}^{2}}\right)(\cos \theta)^{2}\left(\sin \theta_{\mathrm{z}}\right)^{3}\right]}
\end{aligned}
$$

where $I_{\mathrm{Th}}=I_{\mathrm{bh}}+I_{\mathrm{dh}}$.

Hay model ${ }^{[15]}$ :

$$
I_{\mathrm{d} \beta}=I_{\mathrm{dh}}\left[\frac{I_{\mathrm{bh}}}{I_{\mathrm{eh}}} \cdot \frac{\cos \theta}{\cos \theta_{\mathrm{z}}}+\frac{1}{2}(1+\cos \beta)\left(1-\frac{I_{\mathrm{bh}}}{I_{\mathrm{eh}}}\right)\right]
$$

where $I_{\mathrm{eh}}=1367[1+0.033 \cos (0.0172024 n)] \cos \theta_{\mathrm{z}}$.

Moreover, in Perez et al. model ${ }^{[16]}$ :

$$
I_{\mathrm{d} \beta}=I_{\mathrm{dh}}\left[\left(1-F_{1}\right)\left(\frac{1+\cos \beta}{2}\right)+F_{1} \frac{a}{b}+F_{2} \sin \beta\right]
$$

where $a=\max [0, \cos \theta] ; b=\max \left[\cos 85^{\circ}, \cos \theta_{\mathrm{z}}\right]$;

$$
F_{1}=\max \left[0, f_{11}+f_{12} \Delta+\frac{f_{13} \theta_{z} \pi}{180}\right] ; F_{2}=f_{21}+f_{22} \Delta+\frac{f_{23} \theta_{z} \pi}{180}
$$

$$
\Delta=\frac{m I_{\mathrm{dh}}}{I_{\mathrm{e}}} ; I_{e}=1367[1+0.033 \cos (0.0172024 n)]
$$

$$
m=\frac{1}{\cos \theta_{\mathrm{z}}+0.5057\left(96.08-\theta_{\mathrm{z}}\right)^{-1.634}} ; \varepsilon_{\mathrm{i}}=\frac{\frac{I_{\mathrm{dh}}+I_{\mathrm{e}}}{I_{\mathrm{dh}}}+5.535 \times 10^{-6} \theta_{\mathrm{z}}^{3}}{1+5.535 \times 10^{-6} \theta_{\mathrm{z}}^{3}} ;
$$
$\varepsilon_{\mathrm{i}}$.

The values of $f_{11}, f_{12}, f_{13}, f_{21}, f_{22}$ and $f_{23}$ refer to [16] based on

For brevity, the four irradiance calculation models are numbered as listed in Table I.

\section{TABLE I. NUMBERING OF CALCULATION MODELS}

\begin{tabular}{cc}
\hline Model & Number \\
\hline Liu and Jordan & 1 \\
Klucher & 2 \\
Perezet al. & 3 \\
Hay & 4 \\
\hline
\end{tabular}

III. COMPARISON AND CORRECTION OF INCLINED SURFACE SOLAR IRRADIANCE CALCULATION MODELS

The solar irradiance data of Beijing (latitude $40^{\circ} \mathrm{N}$, longitude $116^{\circ} \mathrm{E}$ ) within a year is selected for comparison with calculated results of the four irradiance calculation models.

The horizontal plane is treated as a particular case of inclined surface whose tilt angle is $\beta=0$ and the reflected irradiance of the plane is 0 . Data of direct solar irradiance and diffuse irradiance on horizontal plane of Beijing city are shown in Figure I.

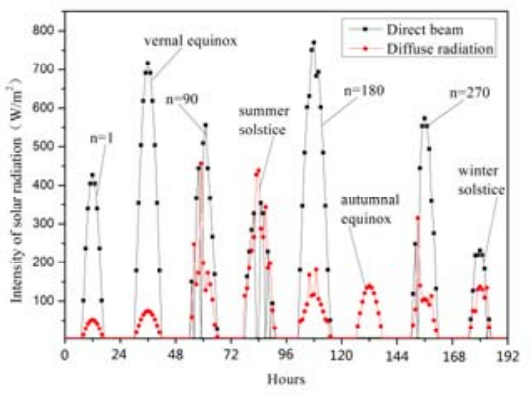

FIGURE I. DIRECT SOLAR IRRADIANCE AND DIFFUSE IRRADIANCE DATA ON HORIZONTAL PLANE OF BEIJING WITHIN A YEAR 
The solar irradiance on inclined surface was calculated from the data of solar irradiance of horizontal plane. With the direct solar irradiance and diffuse irradiance data on horizontal plane of Beijing over a year, direct solar irradiance and diffuse irradiance on inclined surface as tilt angle $\beta=0$ were calculated using the four models. The results were compared with the solar irradiance data of Beijing and analyzed. For better comparison and analysis, four representative days were selected, i.e. vernal equinox, summer solstice, autumnal equinox, and winter solstice, to cover various weather conditions (totally clear at vernal equinox, cloudy at summer solstice, totally overcast at autumnal equinox and clear at winter solstice). Figure II (a), (b), (c), and (d) show the calculated values of diffuse solar irradiance on horizontal surface during vernal equinox, summer solstice, autumnal equinox, and winter solstice, respectively.

Figure II shows that when direct and diffuse solar irradiance values of horizontal surface are calculated, the calculated results of models 1,3 and 4 totally agree with the

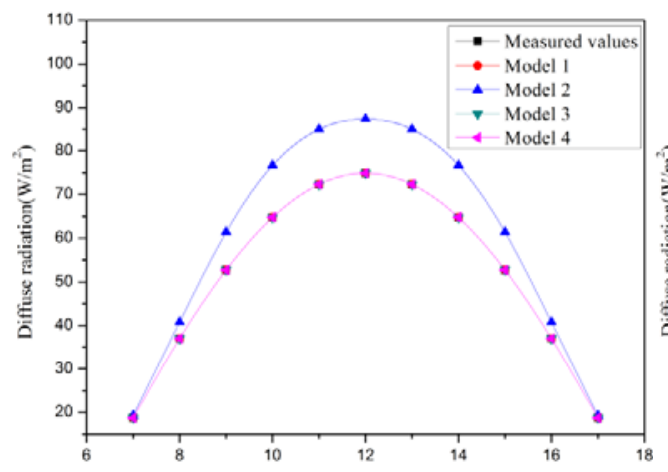

(A)

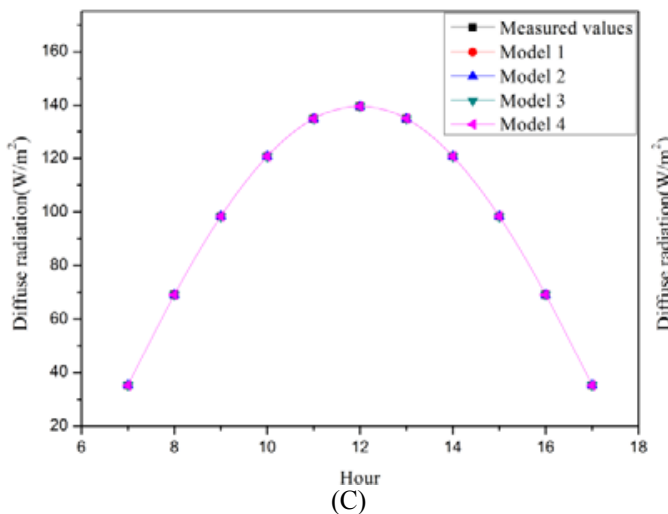

(C) solar irradiance data of Beijing, while that of Model 2 on a cloudless day (direct irradiance above 0 ) are relatively higher. Except for Model 2, models 1, 3 and 4 can exactly calculate the solar irradiance on horizontal surface. Therefore, Model 2 is corrected for adapting to the solar radiations on horizontal plane and inclined surface with relatively small tilt angle. Through analysis and studies, Model 2 (Klucher model) is corrected as following (for convenience, the correction model is named as Model 2'):

$$
\begin{aligned}
& I_{\mathrm{d} \beta}=I_{\mathrm{dh}} \cdot \frac{1+\cos \beta}{2} \cdot\left[1+\left(1-\frac{I_{\mathrm{dh}}^{2}}{I_{\mathrm{Th}}^{2}}\right)\left(\sin \frac{\beta}{2}\right)^{3}\right] \\
& {\left[1+\left(1-\frac{I_{\mathrm{dh}}^{2}}{I_{\mathrm{Th}}^{2}}\right)\left(\cos ^{2} \theta-\cos ^{2} \theta_{\mathrm{z}}\right)\left(\sin \theta_{\mathrm{z}}\right)^{3}\right]}
\end{aligned}
$$



Hour
(B)

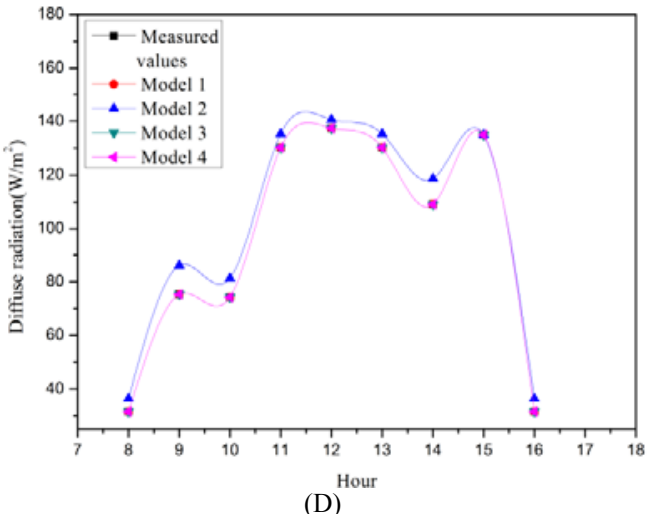

(D)

FIGURE II. CALCULATED VALUES OF DIFFUSE SOLAR IRRADIANCE ON INCLINED SURFACE $\left(\mathrm{B}=0^{\circ}\right)$

\section{CALCUlated RESUlts AND ANALYSIS}

To learn about the features of each calculation models more clearly, based on the direct solar irradiance and diffuse solar irradiance data on horizontal plane of Beijing within a year, by models 1, 2, 3, 4 and Model 2', direct solar irradiance, diffuse irradiance and reflected irradiance on inclined surfaces with tilt angles at $\beta=15^{\circ}, \beta=45^{\circ}$, and $\beta=90^{\circ}$ are calculated. According to $\mathrm{n}$ values $(n=1$ for January $1 \mathrm{st})$, four days are approximately evenly selected within a year for comparison below.
When $n=1$ Model 4 obtains the greatest calculated result, those of Model 3 and Model 2 are less, and that of model one is the least. When $n=90$, Models 2 and 3 perform better than models 4 and 2', while Model 1 gets the smallest variation. Model 2 also well perform in case of $n=180$, while Model 4 gives the worse result. Moreover, the comparison between Fig. IV and Figure II suggests the magnitude relationships of calculated result of the five models is about the same when $n=270$ and $n=90$. Thus, compared with the results of other models, as $\mathrm{n}$ increases, that of Model 4 decreases from the 
maximum gradually to the minimum (reaching the minimum at $n=172$, around summer solstice) and then increases gradually. Besides, the calculated result of Model 2' is always a bit lower than that of model 2; that of Model 1 is the least except in summer.

As Figure III to Figure VI show, increasing the tilt angle of inclined surface, the difference between calculated results of models widens. At sunrise and sunset, the calculated results of models 3 and 4 differ quite greatly from the diffuse irradiance on horizontal plane, and the differences increase with the tilt angle of inclined surface. This phenomenon becomes the most predominant when $n=1$ and $n=180$ (in winter and summer). In addition, when the tilt angle increases from $45^{\circ}$ to $90^{\circ}$, the calculated values of diffuse irradiance of the five models gradually decrease; and when $\beta=90^{\circ}$, all the calculated values of the models are smaller than diffuse irradiance on horizontal plane (excluding those when $n=1$ ).

Table II lists the time-dependent horizontal plane ratios (ratio=diffuse irradiance/direct irradiance) of the abovementioned four days. The ratio slight changes when $n=1$, and a single peak can be observed in the time-varied history of diffuse irradiation; abrupt increase of the ratio is observed for the remaining values of $n$, causing multiple peaks of diffuse irradiation as time varies. Furthermore, to larger ratio corresponds larger diffuse irradiation. The ratio reflects weather condition of that day within some extent, thus it can affect the magnitude of diffuse irradiation and the timedependent trend.
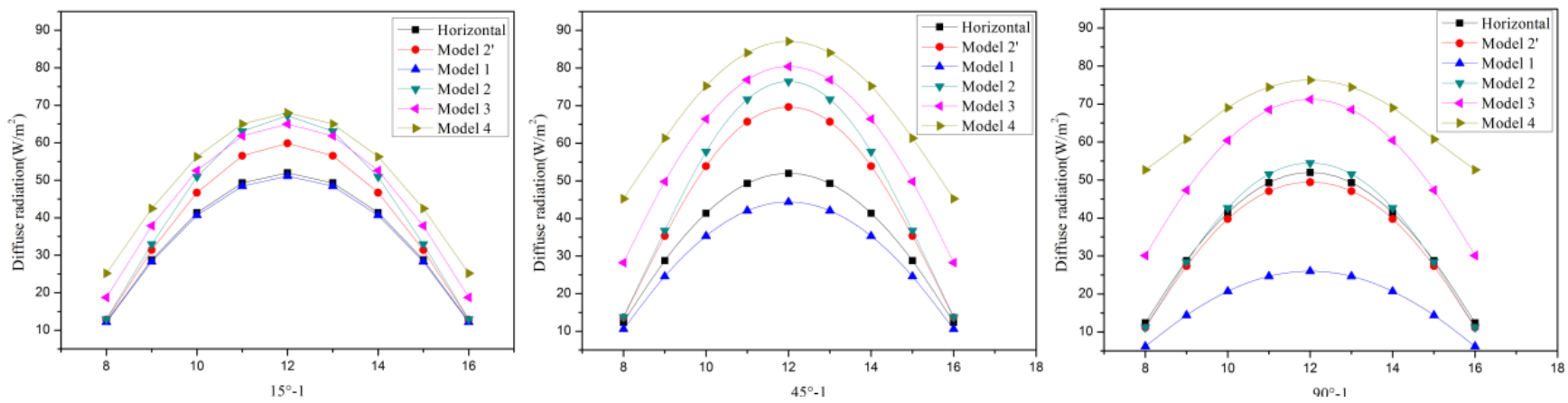

FIGURE III. VARIATION OF CALCULATED VALUE VARYING TILT ANGLE WHEN N=1
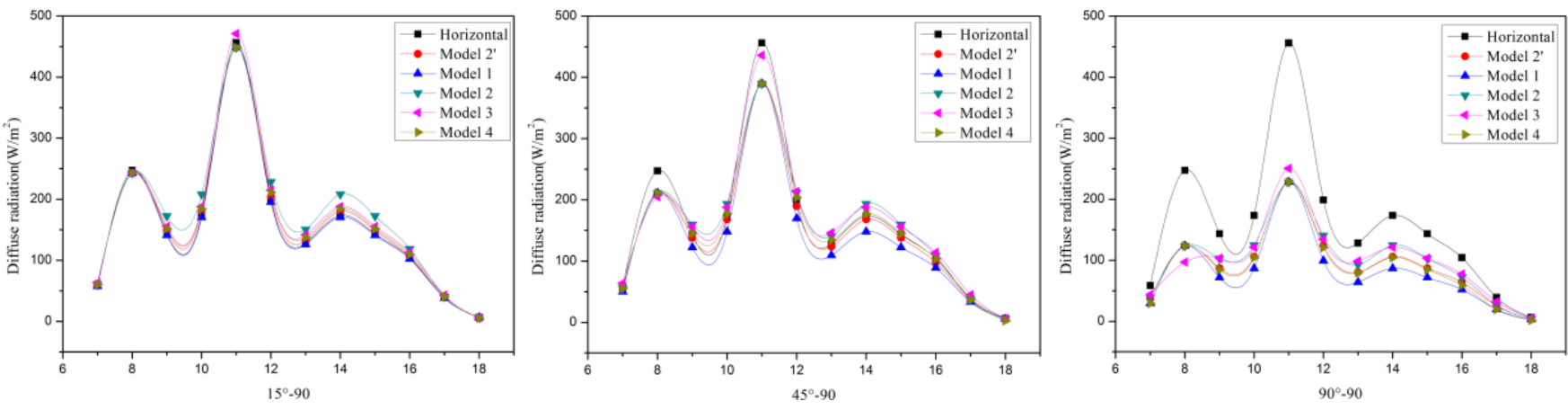

FIGURE IV. VARIATION OF CALCULATED VALUE VARYING TILT ANGLE WHEN N=90
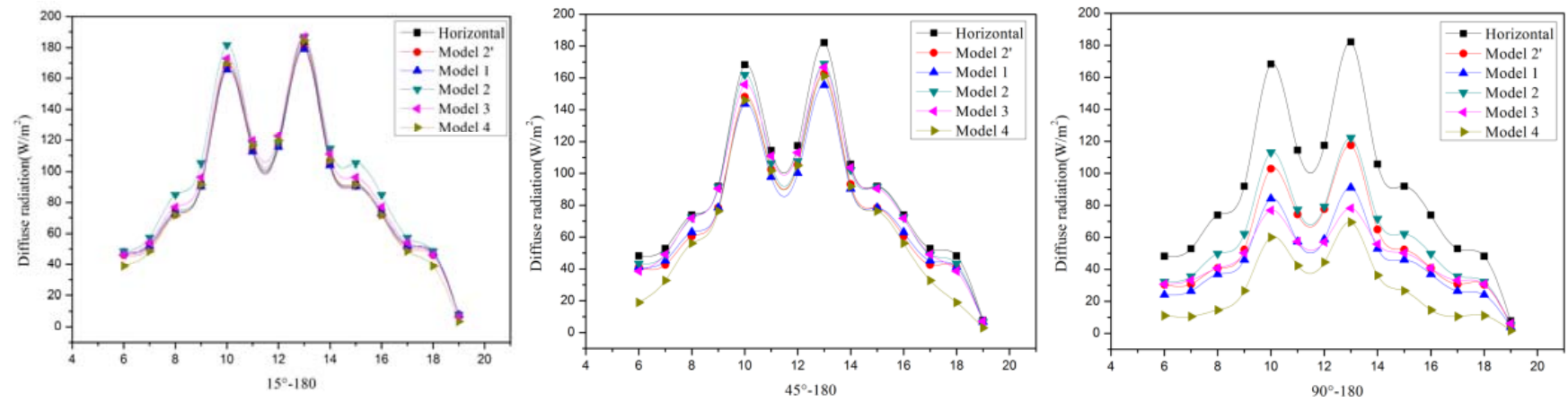

FIGURE V. VARIATION OF CALCULATED VALUE VARYING TILT ANGLE WHEN N=180 

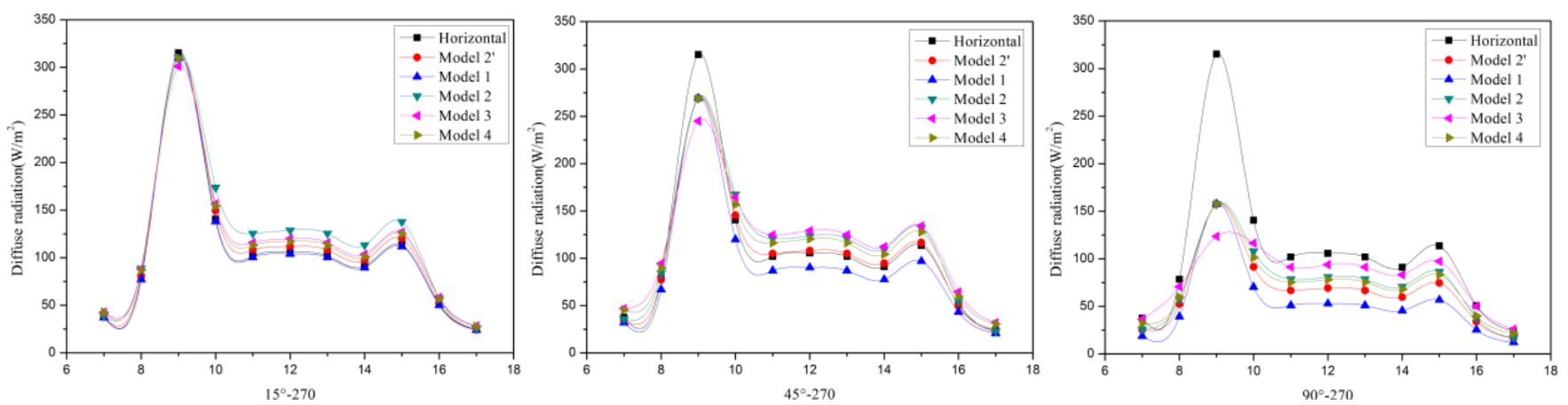

FIGURE VI. VARIATION OF CALCULATED VALUE VARYING TILT ANGLE WHEN N=270

TABLE II. HORIZONTAL PLANE RATIOS (RATIO=DIFFUSE IRRADIANCE/DIRECT IRRADIANCE) VARYING WITH TIME

\begin{tabular}{ccccc}
\hline Time (h) & $\boldsymbol{n = 1}$ & $\boldsymbol{n}=\mathbf{9 0}$ & $\boldsymbol{n = 1 8 0}$ & $\boldsymbol{n}=\mathbf{2 7 0}$ \\
\hline 7 & - & 0.390 & 0.152 & 0.316 \\
8 & 0.121 & $\infty$ & 0.152 & 0.316 \\
9 & 0.121 & 0.390 & 0.152 & $\infty$ \\
10 & 0.121 & 0.390 & 0.266 & 0.316 \\
11 & 0.121 & $\infty$ & 0.152 & 0.184 \\
12 & 0.121 & 0.390 & 0.152 & 0.184 \\
13 & 0.121 & 0.230 & 0.266 & 0.184 \\
14 & 0.121 & 0.390 & 0.152 & 0.184 \\
15 & 0.121 & 0.390 & 0.152 & 0.316 \\
16 & 0.121 & 0.390 & 0.152 & 0.184 \\
17 & - & 0.230 & 0.152 & 0.184 \\
\hline
\end{tabular}

Note: $\infty$ denotes that direct irradiation is 0 , i.e. overcast day

\section{CONCLUSIONS}

Focusing on Beijing, the present work used Liu and Jordan, Klucher, Hay, and Perez models to calculate solar irradiation on inclined surface and corrected Klucher model at tilt angle $\beta=0^{\circ}$. For further understanding, the tilt angles of $\beta=15^{\circ}, \beta=45^{\circ}$ and $\beta=90^{\circ}$ were selected for the comparison and analysis of the above-mentioned four models and the correction model, and the following conclusions were addressed:

The comparison of the calculated results of the models considered shows that increasing $n$ those of Model 4 decrease from a maximum to a minimum among the models (around summer solstice) and then gradually increase.

The influences of tilt angle of inclined surface on each model are as follows: a) increasing tilt angle the difference in calculated values of diffuse irradiance between the models increases; b) the calculated results of models 3 and 4 relatively greatly differ from diffuse irradiation on horizontal plane at sunrise and sunset, and the differences increase with the increase of tilt angle; this phenomenon becomes the most predominant when $n=1$ and $n=180$ (in winter and summer); c) increasing the tilt angle from $45^{\circ}$ to $90^{\circ}$, the calculated values of diffuse irradiation of the five models gradually decrease. At $\beta=90^{\circ}$, all the calculated values of the models are smaller than the diffuse irradiation on horizontal plane (excluding those when $\mathrm{n}=1$ ).
The corrected Klucher model is more suitable for the horizontal plane $\left(\beta=0^{\circ}\right)$ and inclined surface with small tilt angle, and the calculated value is always smaller than that calculated by Klucher model.

The ratio between diffuse and direct irradiance can affect the magnitude of diffuse irradiation and its variation trend with time, while its effect on the magnitude relationship among the models can be neglected.

\section{ACKNOWLEDGMENTS}

This study was sponsored by: (1) the National Science Foundation of China (NSFC), Project No. 51408278, (2) the National Science Foundation of China (NSFC), Project No. 51366004, and (3) the Jiangxi Provincial Key Technology R\&D Program, China, Project No. 20141BBE50041.

\section{REFERENCES}

[1] El-Sebaii A A, Al-Hazmi F S, Al-Ghamdi A A, et al. Global, direct and diffuse solar radiation on horizontal and tilted surfaces in Jeddah, Saudi Arabia. Applied Energy, 2010, 87(2):568-576.

[2] Karakoti I, Das P K, Singh S K. Predicting monthly mean daily diffuse radiation for India. Applied Energy, 2012, 91(1):412-425.

[3] Notton G, Poggi P, Cristofari C. Predicting hourly solar irradiations on inclined surfaces based on the horizontal measurements: Performances of the association of well-known mathematical models. Energy Conversion \& Management, 2006, 47(13-14):1816-1829.

[4] Pandey C K, Katiyar A K. A comparative study of solar irradiation models on various inclined surfaces for India. Applied Energy, 2011, 88(4):1455-1459.

[5] Amrouche B, Pivert X L. Artificial neural network based daily local forecasting for global solar radiation[J]. Applied Energy, 2014, 130(5):333-341.

[6] Pandey C K, Katiyar A K. Hourly solar radiation on inclined surfaces. Sustainable Energy Technologies \& Assessments, 2014, 6:86-92.

[7] Cheng C L, Jimenez C S S, Lee M C. Research of BIPV optimal tilted angle, use of latitude concept for south orientated plans. Renewable Energy, 2009, 34(6):1644-1650.

[8] Handoyo E A, Ichsani D, Prabowo. The Optimal Tilt Angle of a Solar Collector . Energy Procedia, 2013, 32(1):166-175.

[9] Stanciu C, Stanciu, D. Optimum tilt angle for flat plate collectors all over the World - A declination dependence formula and comparisons of three solar radiation models. Energy Conversion \& Management, 2014, 81(2):133-143.

[10] Ajdid R, Ouassaid M, Maaroufi M. The performances of PV technologies in solar tracking system under Moroccan climatic conditions. Conférence Internationale En Science Et Technologies Electriques Au Maghreb - Cistem. 2016. 
[11] Clarke J, Athienitis A K, Santamouris M, et al. Energy simulation in building design. A. Hilger, 2nd Edition,2001.

[12] Liqun He, Lixing Ding. Fundamentals of thermal physics for solar building (In Chinese). University of science and technology of China press, 2011.

[13] Liu B, Jordan R C. The long-term average performance of flat-plate solar-energy collectors. Solar Energy, 1963, 7(2):53-74.

[14] Klucher T M. Evaluation of models to predict insolation on tilted surfaces. Solar Energy, 1979, 23(2):111-114.

[15] Junkui Cui,Wenting Chen. Simulation analysis of the best angle for solar collector heating system in beijing area (In Chinese). Building Energy Efficiency, 2015(5):49-51

[16] Perez R, Ineichen P, Seals R, et al. Modeling daylight availability and irradiance components from direct and global irradiance. Solar Energy (Journal of Solar Energy Science and Engineering); (USA), 1990, 44:5(5):271-289. 